\title{
Presence of Strongyle Infection in Thoroughbred Horses of Punjab Province, Pakistan
}

\author{
Muhammad Amjad Khan ${ }^{1,2}$, Nabila Ruhi ${ }^{2}$, and Hina Qaiser ${ }^{1^{*}}$ \\ ${ }^{1}$ Department of Biology, Lahore Garrison University, Lahore, Pakistan \\ ${ }^{2}$ Department of Zoology, University of the Punjab, Lahore, Pakistan \\ *Corresponding author. Email: hinaqaiser@lgu.edu.pk \\ https://doi.org/10.12982/CMUJNS.2020.0015
}

Received: January 6, 2019

Revised: April 18, 2019

Accepted: July 15, 2019

\begin{abstract}
Strongyle infection among horses is complex and produces an inflammatory enteropathy resulting in impaired intestinal motility and microcirculation. In this study, presence of strongylosis was determined by fecal examination for nematode eggs in thoroughbred horses of Punjab Province, Pakistan. A cross sectional study was conducted from January to December 2017 in four districts of Punjab province namely Sahiwal, Lahore, Sargodha and Mandi Baha-ud-Din. A total of 2,400 fecal samples were collected from horses and examined by direct smear and floatation method. Presence was calculated according to region, month, season, age and gender. In addition, the effect of meteorological factors such as temperature, humidity and rainfall were also analyzed. The findings revealed that out of 2,400 samples, 973 (40.54\%) were found positive for strongylosis. There was a statistically significant difference between seasons and months with disease occurrence. The parasite and host form an association to form an epidemiological danger. The existence and localization of this association must be recognized well in time to control the problem.
\end{abstract}

Keywords: Strongylosis, Nematodes, Horses, Presence, Infestation

\section{INTRODUCTION}

Livestock, an indispensable part of agriculture sector, epitomizes a foremost national resource. It plays a vital role in attaining and improving living standards of both developing and developed nations (Smith et al., 2013). According to Pakistan Livestock Census, equine population is 4.76 million 
approximately. The livestock backs about $56.3 \%$ of the value of agriculture and virtually $11 \%$ to the agricultural gross domestic product in the country (Rehman et al., 2017). Many factors influence the health and productivity of equines. Parasitism is an imperative limitation of efficacious horse rearing around the world and many species of parasites can cause serious infections in equines especially horses (Uslu and Guclu, 2007). Parasitic ailments can be a major constraint for the economy of poor nations and are seldom linked to high mortality rates and have inimical effects on the stakeholders of food security (Goraya et al., 2013). They are accountable for immunosuppression, predisposing the animals to other illnesses. Some parasitic infections may even cause deaths when the control measures remain unkempt (Fleurance et al., 2007). Strongyle nematodes are the chief internal parasites of the equines covering almost $50 \%$ of the over 100 species and documented with an infection rate of $58.5 \%$ (Nielsen, 2012). Henceforth, the detection of gastrointestinal nematode infections holds an important position in studying parasite life-cycles, epidemiology, population biology and systematics, essential for the diagnosis and control.

It is therefore mandatory to investigate the disease dynamics for better prevention and therapeutic strategies. Research reports on horse parasites in Pakistan are extremely scanty with almost non-existent scientific reports on the presence of strongylosis in horses and their therapies. This study focused on the documentation of presence and intensity of strongylosis in thoroughbred horses in four districts of Punjab province to procure baseline data so as to design effective control options.

\section{MATERIALS AND METHODS}

\section{Study area and sample collection}

The study was undertaken from January to December 2017 in 4 selected districts (Lahore, Sahiwal, Sargodha and Mandi Baha-ud-Din) of Punjab, Pakistan. A total of 2,400 faecal samples of thoroughbred horses $(1,200$ geld \& 1,200 mares), 600 per district ( 50 per month per district) for a period of 1 year were examined randomly for the presence of strongyle eggs. Simple random sampling method was used to select individual study animals.

In Sahiwal, samples were collected from remount stallion stables of Horse Mules and Cattle Breeding of Qadirabad, Yousafwala, Iqbalnagar, Kassowal, Noorshah, Harappa and Ghaziabad towns. In these areas the Government of Pakistan (Ministry of Defence) has leased out lands to the tenants for the breeding and rearing of equines. These areas comprise a nursery for supply of horses to Pakistan Army for operational use in the hilly terrain.

Lahore district is hub of equisterian activities where polo tournaments and horse races are routine features. The survey was carried out at Military Veterinary Detachment Lahore Cantonment, Lahore Garrision Saddle \& Polo Club Fortress 
Stadium, Lahore Polo Club, Lahore Race Club and from Manga Mandi, Sunder, Kala shah Kaku, Bedian, Barki and Shahdra towns.

The Remount Depot Sargodha and Shapur, Mitha Lak, Chak 71 NB, Khan Muhammad Wala, Jhal Chakian, Shaheen Abad, Kot Sultan, Military stud farms were visited for sample collection in Sargodha. The equines reared in these towns are well known for their excellence in polo and tent pegging. The population of equines is maximum in this district compared with other districts of Punjab province.

In Mandi Baha ud din the samples were collected from North Charge / Horse breeding stud of Remount Depot Mona.

Information regarding the animal was collected according to a predesigned questionnaire. Systematic investigation was done according to the parasitic infection. Clinical examination of each animal was also performed; rectal temperature, pulse rate, respiration rate, palpation of lymph nodes, colour of conjuctiva, texture of faeces, urine colour, presence of any swelling on the extremities and presence of any ectoparasite on the body was documented.

\section{Study design and methodology}

The villages and horse stud farms of four districts mentioned above were visited every month for the entire course of study. Simple random sampling method was used to select individual study animals. On each visit, a total of 200 faecal samples were collected (50 from each district per month). These samples were examined by direct smear and flotation techniques. Presence of infection was recorded as month, season and area wise. The age, sex and breed of each animal was also furnished. The presence of disease in different districts of Punjab province was recorded following the formula described by Neilson et al. (2014).

$$
\text { Presence }=\frac{\text { No. of horses infected with stronglyes }}{\text { No. of horses examined }} \times 100
$$

To record the seasonal presence, year was apportioned into four seasons i.e. winter (Nov-Feb), spring (Mar-Apr), summer (May-Aug) and autumn (SepOct). To record the age wise presence, the horses were divided in four age groups (1-5, 6-10, 11-15 and 16-20 years). The presence percentage of an age group was calculated out of total number of horses in that particular age group. The age detail of all the 2,400 examined horses has been shown in Table 1 .

Table 1. Age structure of examined horses.

\begin{tabular}{cccccc}
\hline Age (years) & Sahiwal & Lahore & Sargodha & Mandi Bah-ud-Din & Total \\
\hline $1-5$ & 190 & 193 & 188 & 184 & 755 \\
$6-10$ & 213 & 230 & 251 & 256 & 950 \\
$11-15$ & 124 & 140 & 120 & 130 & 514 \\
$16-20$ & 73 & 37 & 41 & 30 & 181 \\
Total & 600 & 600 & 600 & 600 & 2,400 \\
\hline
\end{tabular}


Presence in relation to meteorological factors including temperature, humidity and rain fall was also determined. Meteorological data for Sahiwal, Lahore, Sargodha and Mandi Baha-ud-Din districts was collected from Pakistan Meteorological Department Gulberg III, Lahore (Table 2).

Table 2. Meteorological Data of Sahiwal, Lahore, Sargodha and Mandi Baha-ud-Din.

\begin{tabular}{|c|c|c|c|c|c|c|c|c|c|c|c|c|c|c|}
\hline Dist & Factors & & Jan & Feb & Mar & Apr & May & June & July & Aug & Sep & Oct & Nov & Dec \\
\hline \multirow{7}{*}{ Sahiwal } & \multirow{3}{*}{$\begin{array}{l}\text { Avg. temperature } \\
\left({ }^{\circ} \mathrm{C}\right)\end{array}$} & Min & \begin{tabular}{|l|}
3.8 \\
\end{tabular} & 6.6 & 12.3 & 17.3 & 22.1 & 26.3 & 26.4 & 25.9 & 22.8 & 17.9 & 10.5 & 6.6 \\
\hline & & $\operatorname{Max}$ & 20.1 & 20.9 & 26.3 & 33.9 & 37.9 & 41.8 & 38.6 & 35.3 & 35.1 & 32.6 & 26.7 & 21.4 \\
\hline & & Mean & 11.9 & 13.8 & 19.3 & 25.6 & 29.0 & 34.5 & 32.5 & 30.6 & 28.9 & 25.3 & 18.6 & 14 \\
\hline & \multirow{3}{*}{$\begin{array}{l}\text { Avg. Relative } \\
\text { Humidity (\%) }\end{array}$} & Min & 53 & 55 & 51 & 35 & 33 & 34 & 49 & 51 & 50 & 48 & 47 & 57 \\
\hline & & $\operatorname{Max}$ & 90 & 88 & 83 & 68 & 58 & 55 & 71 & 74 & 80 & 84 & 86 & 88 \\
\hline & & Mean & 71.5 & 71.5 & 67 & 51.5 & 45.5 & 44.5 & 60 & 62.5 & 65 & 66 & 66.5 & 72.5 \\
\hline & \multicolumn{2}{|c|}{ Rainfall (mm) } & 0.1 & 25.2 & 58.2 & 42.5 & 16.3 & 15.2 & 76.1 & 0.1 & 34.1 & 1 & 4 & 0 \\
\hline \multirow{7}{*}{ Lahore } & \multirow{3}{*}{$\begin{array}{l}\text { Avg. temperature } \\
\left({ }^{\circ} \mathrm{C}\right)\end{array}$} & Min & 4. & 6.9 & 12. & 17.8 & 22.8 & & & & 9 & 19.4 & 2 & 6.1 \\
\hline & & $\operatorname{Max}$ & 18.8 & 20 & 25.6 & 32.9 & & 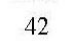 & & 36.5 & 33.6 & 31.7 & 26.3 & 20 \\
\hline & & Mean & 11.6 & 13.5 & 19.0 & 25.4 & 30.5 & 34.9 & 31.8 & 31.5 & 28.8 & 25.6 & 19.3 & 13.1 \\
\hline & \multirow{3}{*}{$\begin{array}{l}\text { Avg. Relative } \\
\text { Humidity (\%) }\end{array}$} & Min & 59 & 58 & 52 & 36 & 32 & 32 & 56 & 54 & 64 & 51 & 47 & 61 \\
\hline & & $\operatorname{Max}$ & 87 & 85 & 75 & 60 & 57 & 49 & 71 & 72 & 83 & 75 & 80 & 86 \\
\hline & & Mean & 73 & 71.5 & 63.5 & 48 & 44.5 & 40.5 & 63.5 & 63 & 73.5 & 63 & 63.5 & 73.5 \\
\hline & \multicolumn{2}{|c|}{ Rainfall $(\mathrm{mm})$} & 6.1 & 25.9 & 49.5 & 115.5 & 33.8 & 44 & 41.1 & 27 & 31.1 & 0 & 5.2 & 11 \\
\hline \multirow{7}{*}{ Sargodha } & \multirow{3}{*}{$\begin{array}{c}\text { Avg. temperature } \\
\left({ }^{\circ} \mathrm{C}\right)\end{array}$} & Min & 4.6 & 7.2 & 13.3 & 17.8 & 22.9 & 28.1 & 28 & 26.4 & 24.4 & 19.0 & 10.3 & 6.7 \\
\hline & & $\operatorname{Max}$ & 20.2 & 20.3 & 24.5 & 31.6 & 36.3 & 41.9 & 37.4 & 36.1 & 33.8 & 30.8 & 26.4 & 20.4 \\
\hline & & Mean & 12.4 & 13.8 & 18.9 & 25.2 & 29.6 & 35 & 32.7 & 31.3 & 29.1 & 24.9 & 18.4 & 13.6 \\
\hline & \multirow{3}{*}{$\begin{array}{l}\text { Avg. Relative } \\
\text { Humidity (\%) }\end{array}$} & Min & 55 & 58 & 53 & 48 & 43 & 55 & 56 & 60 & 59 & 57 & 55 & 62 \\
\hline & & $\operatorname{Max}$ & 89 & 88 & 80 & 72 & 61 & 1. & 78 & 81 & 81 & 83 & 85 & 88 \\
\hline & & Mean & 72 & 73 & 66.5 & 60 & 52 & 64 & 67 & 70.5 & 70 & 70 & 75 & 75 \\
\hline & \multicolumn{2}{|c|}{ Rainfall (mm) } & 22.2 & 22 & 35.2 & 34 & 39.4 & 39 & 76.1 & 96 & 135.1 & 14.3 & 4 & 1 \\
\hline \multirow{7}{*}{$\begin{array}{c}\text { Mandi } \\
\text { Baha-ud- } \\
\text { Din }\end{array}$} & \multirow{3}{*}{$\begin{array}{l}\text { Avg temperature } \\
\left({ }^{\circ} \mathrm{C}\right)\end{array}$} & Min & 5.6 & 8.2 & 12.9 & 17.5 & 22.1 & 26.5 & 26.7 & 25.8 & 23.7 & 19.2 & 11.2 & 7.4 \\
\hline & & $\operatorname{Max}$ & 20.2 & 20.5 & 25.3 & 31.7 & 36.4 & 41 & 36. & 35.9 & 33.3 & 31.4 & 25.5 & 19.6 \\
\hline & & Mean & 12.9 & 14.4 & 19.1 & 25.1 & 29.3 & 34.2 & 31.7 & 30.9 & 28.5 & 25.3 & 18.4 & 13.5 \\
\hline & \multirow{3}{*}{$\begin{array}{l}\text { Avg. Relative } \\
\text { Humidity (\%) }\end{array}$} & Min & 68 & 63 & 58 & 46 & 48 & 32 & 62 & 64 & 67 & 62 & 60 & 67 \\
\hline & & $\operatorname{Max}$ & 80 & 90 & 85 & 73 & 78 & 53 & 82 & 84 & 87 & 88 & 91 & 92 \\
\hline & & Mean & 74 & 76.5 & 71.5 & 59.5 & 63 & 43.5 & 72 & 74 & 73.5 & 75 & 75.5 & 79.5 \\
\hline & \multicolumn{2}{|c|}{ Rainfall (mm) } & 1.3 & 20.3 & 126.3 & 58.5 & 40.2 & 41.6 & 178 & 189 & 235.1 & 25.3 & 18 & 0 \\
\hline
\end{tabular}

Note: $*$ Source $=$ Pakistan Meteorological Department.

\section{Parasitological examination}

Approximately five to ten grams of fresh faeces were collected directly from the rectum in separate polythene bags, properly labelled and transported to the laboratory of Department of Zoology, University of the Punjab, Lahore, Pakistan. They were subjected to direct microscopic examination on the same day to detect the worms and eggs (Zajac and Conboy, 2012). Three slides were examined from each sample and an average was taken. The samples found negative were re-examined by using centrifugal floatation method before declaring as negative.

The positive samples were further subjected to eggs per gram (EPG) counting to find out the number of eggs per gram of the faeces by the method described by Mohammed et al. (2015). As per the EPG count, the infection was rated as light (50-799 EPG), moderate (800-1,200 EPG) and severe (>1,200 EPG) (Haimanot et al., 2015). 


\section{Statistical analysis}

To analyze and compare the mean \pm SEM values for epidemiology, the statistical analysis was performed by using analysis of variance (ANOVA) at $P=0.05$. Chi square test was performed to assess the dependence of degree of infection on certain risk factors. The data were analyzed by using GraphPad Prism programme version 5.00 .

\section{RESULTS}

\section{Overall presence in Punjab Province}

A total of 2,400 thoroughbred horses were examined of which 973 were found positive for strongylosis. The overall presence was thus $40.54 \%$.

The strongylosis in horses in all the four districts of Punjab indicated that infection rate was highest at Sargodha district (43.33\%) followed by Sahiwal (40.83\%) then Mandi Baha-ud-Din district $(39.83 \%)$ whereas the lowest was noted at Lahore district (38.16\%) (Figure 1A). Details are shown in Figure 1A. There was no statistically significant difference $(P=0.05)$ in presence of strongylosis infection of horses between four sites.

Analysis of strongylosis presence of horses by months showed that there were statistically significant month-wise variations $(P<0.05)$. The higher infection presence $(63 \%)$ was noted during the month of May followed by June while the lowest (12\%) was noted during February (Figure 1B).

Season wise analysis of the presence rate revealed the maximum frequency (61.37\%) of infection documented during summer followed by autumn then spring whereas the lowest (19.25\%) was recorded during winter. The data suggest a highly significant increase in presence percentage during summer season at $P=0.05$ (Figure 1C).

Percentage of animals infected did not appear to differ with the age of horses (Figure 1D). The results indicated almost equal presence of disease in all the age groups $(40.26 \%, 40.73 \%, 40.66 \%$ and $40.33 \%$ for horses aged between 1-5, 6-10, 11-15 and 16-20 years respectively) with no significant difference at $P=0.5$.

Gender based analysis indicated the presence to be $40.91 \%$ in geldings followed by $40.16 \%$ in mares. The findings suggested that there was an insignificant relationship between the gender and disease frequency at $P=0.05$. It can be inferred that incidence of the disease was independent of animal age. 


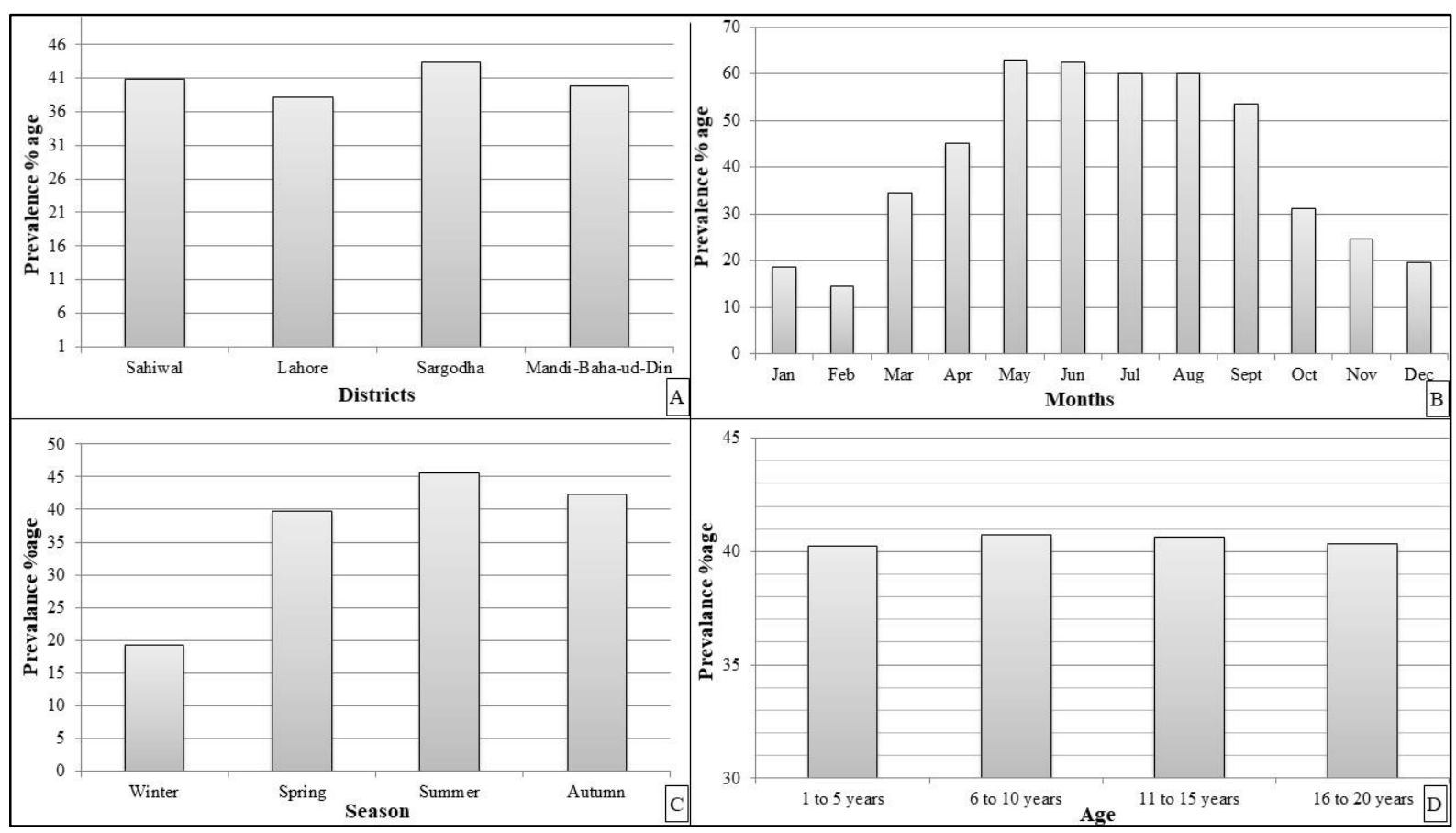

Figure 1. Presence percentage of strongylosis in horses (A) District-wise presence (B) Month-wise presence (C) Season-wise Presence (D) Agewise presence.

\section{Infection presence with respect to the environmental factors}

The maximum/minimum and monthly presence of strongylosis with relation to environmental temperature, mean humidity and rainfall at four districts of Punjab has been shown in Table 3. It was noted that the infection was directly proportional to the environmental temperature which had a statistically significant effect $(P<0.05)$. The maximum presence percentage was observed between the temperature range of 28.9 to $32.7{ }^{\circ} \mathrm{C}$ whereas minimum values were documented between 13.0 to $14.3{ }^{\circ} \mathrm{C}$ in all the four districts. Sargodha district harbored the highest number of infected individuals (76\%) at mean temperature of $32.7{ }^{\circ} \mathrm{C}$ and least number of cases $(14 \%)$ were reported at $13.5{ }^{\circ} \mathrm{C}$. In case of Mandi Baha-ud-Din, the presence of strongylosis was recorded maximum (68\%) at $29.2{ }^{\circ} \mathrm{C}$ and minimum at $13.5{ }^{\circ} \mathrm{C}$. The strongylosis burden for Sahiwal was documented maximum $(66 \%)$ at mean temperature $28.9{ }^{\circ} \mathrm{C}$ and minimum $(10 \%)$ at $13.7{ }^{\circ} \mathrm{C}$. Overall presence of strongylosis at Punjab province was recorded maximum $(67 \%)$ at mean temperature of $31.2{ }^{\circ} \mathrm{C}$ and minimum presence $(12.5 \%)$ at mean temperature of $13.6{ }^{\circ} \mathrm{C}$.

The effect of relative humidity on the presence of strongylosis infection indicated that moderate humid environment favors the presence of strongylosis among horses. The relationship between the relative humidity and infection was statistically significant at $P=0.05$. As the level of humidity escalated, progressive decrease in the incidence of the disease was witnessed. Maximum presence was recorded between $63.5 \%$ to $65 \%$ mean relative humidity, however the disease 
frequency dejected above mean relative humidity of $70 \%$ at all the areas studied. Overall Presence of strongylosis at Punjab province was recorded maximum $(67 \%)$ at mean relative humidity of $64.62 \%$ and minimum presence $(12.5 \%)$ at mean relative humidity of $73.37 \%$.

The statistical analysis of the effect of rainfall on infection presence did not reveal the significant results at $P=0.05$. The presence of infection did not alone support the growth of parasite in the horses. Presence of strongylosis at Sahiwal district was recorded maximum $(66 \%)$ at $34.1 \mathrm{~mm}$ rain fall, Lahore $(58 \%)$ at $41.1 \mathrm{~mm}$ rain fall, Sargodha (68\%) at $76.1 \mathrm{~mm}$ rain fall and Mandi Bahaud-Din (68\%) at $79.2 \mathrm{~mm}$ rain fall. Presence of strongylosis at Sahiwal district was recorded minimum $(10 \%)$ at $25.5 \mathrm{~mm}$ rain fall, Lahore $(14 \%)$ at $11 \mathrm{~mm}$ rain fall, Sargodha (14\%) at $22.2 \mathrm{~mm}$ rain fall and at Mandi Baha-ud-Din $(12 \%)$ at $20.3 \mathrm{~mm}$ rain fall. Overall Presence of strongylosis at Punjab province was recorded maximum $(67 \%)$ at $38.6 \mathrm{~mm}$ rain fall and minimum presence $(12.5 \%)$ at $19.62 \mathrm{~mm}$ rain fall.

\section{Degree of strongylosis infection with different risk factors}

The samples declared positive through qualitative parasitological examination were subjected to EPG count to estimate the degree of infection. Accordingly, out of 973(40.54\%) positive specimens, 383(39.3\%), 334(34.2\%) and 256(26.3\%) were found to be lightly, moderately and massively infested respectively. Furthermore, the degree of infection was assessed with respect to gender, age group and season and the results are summarized in Table 4. The statistical analysis (Chi-square test) of the data revealed that the severity of infection was influenced by all the risk factors under consideration $(P=0.05)$.

\section{DISCUSSION}

The presence of strongyles in the study area may be attributed to the suitability of the climatic conditions (Table 2) of all the four districts for survival and transmission of the parasites. The present study when compared to different study areas showed alike infection rate of strongylosis nematode. Pilo et al. (2012), during a study on 46 Sardinian horses suffering from strongylosis in Italy demonstrated that $S$. vulgaris larvae were found in $39 \%$ whereas the detection rate in faeces was only $4 \%$. Saeed et al. (2010) reported that infection rate of strongyles (S.vulgaris, S.edentatus and S.equi) was $58.5 \%$ among the equines studied.

The overall month-wise presence percentage ranged from 14.5 to $62.5 \%$ in a calendar year. As regard to season wise presence, it was the highest (61.37\%) during summer followed by autumn then spring and the lowest $(19.25$ $\%$ ) during winter. The present findings are in good agreement with that of 
Jubb et al. (1985), Krecek et al. (1987) and Saeed et al. (2010) wherein higher eggs excretion was observed in spring and summer. This may be because that elevated temperatures are apt for larval development and colossal contamination of infective larvae may take place in summers and early autumn when young susceptible horses are present (Wannas et al., 2012).

Table 3. Presence of strongylosis with respect to environmental factors.

\begin{tabular}{|c|c|c|c|c|c|c|c|c|c|c|c|c|c|c|}
\hline District & Factors & Jan & Feb & Mar & Apr & May & June & July & Aug & Sep & Oct & Nov & Dec & F value \\
\hline \multirow{3}{*}{ Sahiwal } & Avg. temperature $\left({ }^{0} \mathrm{C}\right)$ & 11.9 & 13.8 & 19.3 & 25.6 & 29.0 & 34.5 & 32.5 & 30.6 & 28.9 & 25.3 & 18.6 & 14 & $9.7432^{*}$ \\
\hline & $\begin{array}{l}\text { Avg. Relative } \\
\text { Humidity (\%) }\end{array}$ & 71.5 & 71.5 & 67 & 51.5 & 45.5 & 44.5 & 60 & 62.5 & 65 & 66 & 66.5 & 72.5 & $13.460^{*}$ \\
\hline & Rainfall (mm) & 0.1 & 25.2 & 58.2 & 42.5 & 16.3 & 15.2 & 76.1 & 60.1 & 34.1 & 1 & 4 & 0 & 3.04773 \\
\hline \multicolumn{2}{|c|}{ Presence of infection (\%) } & 24 & 10 & 24 & 40 & 52 & 56 & 58 & 58 & 66 & 36 & 40 & 26 & \\
\hline \multirow{3}{*}{ Lahore } & Avg. temperature $\left({ }^{\circ} \mathrm{C}\right)$ & 11.6 & 13.5 & 19.0 & 25.4 & 30.5 & 34.9 & 31.8 & 31.5 & 28.8 & 25.6 & 19.3 & 13.1 & $6.7544^{*}$ \\
\hline & $\begin{array}{l}\text { Avg. Relative } \\
\text { Humidity (\%) }\end{array}$ & 73 & 71.5 & 63.5 & 48 & 44.5 & 40.5 & 63.5 & 63 & 73.5 & 63 & 63.5 & 73.5 & $12.061^{*}$ \\
\hline & Rainfall (mm) & 6.1 & 25.9 & 49.5 & 115.5 & 33.8 & 44 & 41.1 & 27 & 31.1 & 0 & 5.2 & 11 & 3.04773 \\
\hline \multicolumn{2}{|c|}{ Presence of infection (\%) } & 22 & 16 & 30 & 38 & 58 & 56 & 58 & 56 & 54 & 34 & 22 & 14 & \\
\hline \multirow{3}{*}{ Sargodha } & Avg. temperature $\left({ }^{0} \mathrm{C}\right)$ & 12.4 & 13.8 & 18.9 & 25.2 & 29.6 & 35 & 32.7 & 31.3 & 29.1 & 24.9 & 18.4 & 13.6 & $7.2696^{*}$ \\
\hline & $\begin{array}{l}\text { Avg. Relative } \\
\text { Humidity (\%) }\end{array}$ & 72 & 73 & 66.5 & 60 & 52 & 64 & 67 & 70.5 & 70 & 70 & 75 & 75 & $11.802 *$ \\
\hline & Rainfall (mm) & 22.2 & 22 & 35.2 & 34 & 39.4 & 39 & 76.1 & 96 & 135.1 & 14.3 & 4 & 1 & 0.00011 \\
\hline \multicolumn{2}{|c|}{ Presence of infection (\%) } & 14 & 20 & 42 & 50 & 74 & 76 & 68 & 62 & 54 & 28 & 18 & 14 & \\
\hline \multirow{3}{*}{$\begin{array}{l}\text { Mandi Baha } \\
\text { ud Din }\end{array}$} & Avg. temperature $\left({ }^{\circ} \mathrm{C}\right)$ & 12.9 & 14.4 & 19.1 & 25.1 & 29.3 & 34.2 & 31.7 & 30.9 & 28.5 & 25.3 & 18.4 & 13.5 & $6.9285^{*}$ \\
\hline & $\begin{array}{l}\text { Avg. Relative } \\
\text { Humidity (\%) }\end{array}$ & 74 & 76.5 & 71.5 & 59.5 & 63 & 43.5 & 72 & 74 & 73.5 & 75 & 75.5 & 79.5 & $21.591^{*}$ \\
\hline & Rainfall (mm) & 1.3 & 20.3 & 126.3 & 58.5 & 40.2 & 41.6 & 178 & 189 & 235.1 & 25.3 & 18 & 0 & 2.42417 \\
\hline \multicolumn{2}{|c|}{ Presence of infection (\%) } & 14 & 12 & 42 & 52 & 68 & 62 & 56 & 56 & 48 & 26 & 18 & 24 & \\
\hline
\end{tabular}

Note: $\mathrm{F}$ critical $=4.30095, *$ indicates the $P$ value is significant at 0.05 .

Table 4. Degree of strongylosis infection associated with various risk factors.

\begin{tabular}{|c|c|c|c|c|c|c|}
\hline \multirow{2}{*}{\multicolumn{2}{|c|}{ Risk factor }} & \multirow{2}{*}{$\begin{array}{c}\text { No of } \\
\text { positives }\end{array}$} & \multicolumn{3}{|c|}{ Degree of infection } & \multirow[t]{2}{*}{$\mathrm{X}^{2}$ value } \\
\hline & & & Low & Moderate & Massive & \\
\hline \multirow{2}{*}{ Sex } & Mares & & $147(29.9 \%)$ & $166(33.8 \%)$ & $178(36.3 \%)$ & \multirow{2}{*}{$59.6778^{*}$} \\
\hline & Geldings & 482 & $236(49.0 \%)$ & $168(35.0 \%)$ & $78(16.0 \%)$ & \\
\hline \multirow{4}{*}{$\begin{array}{l}\text { Age } \\
\text { (years) }\end{array}$} & $1-5$ & 304 & $72(23.6 \%)$ & $98(32 \%)$ & $134(44.4 \%)$ & \multirow{4}{*}{$86.3853^{*}$} \\
\hline & $6-10$ & 387 & $40(10.3 \%)$ & $135(35.0 \%)$ & $212(54.7 \%)$ & \\
\hline & $11-15$ & 209 & $63(30.1 \%)$ & $82(39.3 \%)$ & $64(30.6 \%)$ & \\
\hline & $16-20$ & 73 & $36(49.3 \%)$ & $22(30.1 \%)$ & $15(20.5 \%)$ & \\
\hline \multirow{4}{*}{ Season } & Winter & 154 & $72(46.8 \%)$ & $54(35.1 \%)$ & $28(18.1 \%)$ & \multirow{4}{*}{$53.7036^{*}$} \\
\hline & Spring & 159 & $60(37.7 \%)$ & $41(25.8 \%)$ & $58(36.5 \%)$ & \\
\hline & Summer & 365 & $73(20.0 \%)$ & $161(44.1 \%)$ & $131(35.9 \%)$ & \\
\hline & Autumn & 169 & $51(30.2 \%)$ & $55(32.5 \%)$ & $63(37.3 \%)$ & \\
\hline
\end{tabular}

Note: * indicate that results are significant at $\mathrm{P}=0.05$. 
In the present study it was noted that animal of either sex was equally affected as 40.91 percent presence was reported in geldings and 40.16 percent in mares. Similar results have also been reported by Saeed et al. (2010). Kvysgaard et al. (2011) conducted a study to determine the presence of strongyle infections in working horses during the dry months in Nicaragua and determined a very high percentage (94\%) of strongyle parasites.

Based on the age wise presence analysis, the horses of all age groups showed almost equal presence of disease and there was no significant difference in presence percentage. This advocated that as per the ubiquitous nature of strongylosis, horses of all ages could acquire the infection. However, the younger animals may display aggravated disease condition (Mohammed et al., 2016). Gasser et al. (2004) described that older horses are often observed to have arterial lesions without a history of specific signs, although signs detected in field cases can be correlated with findings at necropsy. The study conducted by Upjohn et al. (2010) in New Zealand also presented no evidence of a significant age effect over the presence of strongylosis among horses. This was also evident in the findings of Saeed et al. (2010), however in contrast we revealed that the intensity of shedding the eggs was not affected by the age of the animals. The current investigation disclosed that age and sex of the animal has no role in the presence percentage of strongylosis at Punjab province.

Overall presence of strongylosis at Punjab province was recorded maximum $(67 \%)$ at mean temperature $31.2{ }^{\circ} \mathrm{C}$, mean relative humidity $64.62 \%$ and $38.6 \mathrm{~mm}$ total rain fall. The minimum presence $(12.5 \%)$ was recorded at mean temperature $13.6{ }^{\circ} \mathrm{C}$, mean relative humidity $73.37 \%$ and at a total rain fall 19.62 $\mathrm{mm}$. Hutchinson et al. (1989) described that hot dry spring weather (pre-wet season) was the most unfavorable for larval development, migration and survival. Our findings projected that hot / humid environment with moderate rain fall favors presence of the disease as these conditions are best suited for the survival and development of free-living stages of strongyle eggs and larvae outside the host. The low temperature, high percentage of relative humidity and heavy rain fall cause decrease in presence percentage as these conditions do not suite the development / survival of strongyle eggs / larvae. This was also in accordance with Hutchinson et al. (1989) and Sipra et al. (1999).

The degree of infection was categorized into low, moderate and massive forms based upon faecal egg output for gender, age and seasons. A significant variation was observed for the severity of infection with the higher infection noticed in females. The results are in agreement with other reports as well (Maqsood et al., 1996). This may be the case because females are more susceptible to parasitism during pregnancy and per-parturient period due to high stress levels and low immunity. The younger horses (aged 1 to 10 years) were also found out to be suffering from massive infection in this study since they lack the strong immunity developed by adults (aged 11 to 20 years) over time. The adults acquire this solid immunity after the primary and subsequent infections. 
The continuous exposure to the acquisition of infective larvae by the adults can stimulate satisfactory immune responses and therefore results in light infections with almost no clinical illness (Lemma and Abera, 2013). High presence with severe infection was recorded during hot rainy seasons which is in line with Nginyi et al. (2001) and Keyyu et al. (2005). These weather conditions play a significant role in larval development and disease transmission (Mohammed et al., 2015).

A control programme can be recommended based on observations made from collected data. Primarily, after completing the somatic migration larvae of large strongyles take another $6-8$ weeks to reach sexual maturity. Furthermore, the prepatent period of strongyles ranges from 9 to 12 months (Requena-Méndez et al., 2013). The presence is throughout the year, maximum in summer, minimum in winter, not affected by the age and sex of animal and favored by hot/humid environment (Uslu and Guclu, 2007). This would lead to heavy economic losses at national level. The control measures taken to recede the potential adverse effects could be effectual if implemented properly. Horses must be dewormed with broad spectrum dewormer like Piperazine adipate, Ivermectin or moxidectin at least twice a year in May/June and November/December (Boersema et al., 1996). Deworming in early summer would ensure expulsion of worms before reaching sexual maturity and deworming in early winter would ensure the expulsion of remainders of summer (Herd, 1993). In broad terms, it is necessary to avoid treatments of strongylosis during the peak winter months and during peak summer months to retard the development of anthelmintic resistance. Deworming agents should be used alternatively to reduce chances of anthelmintic resistance (Nielsen et al., 2007). For awareness of breeders a campaign on prevention of strongylosis may be launched through electronic and print media by the Livestock department.

\section{ACKNOWLEDGEMENTS}

This research was supported by grants funded by University of the Punjab, Lahore Pakistan.

\section{REFERENCES}

Boersema, J., Eysker, M., Maas J., and Van Der Aar, W. 1996. Comparison of the reappearance of strongyle eggs in foals, yearlings, and adult horses after treatment with ivermectin or pyrantel. Veterinary Quarterly. 18(1): 7-9. https://doi.org/10.1080/01652176.1996.9694602 
Fleurance, G., Duncan, P., Fritz H., Cabaret, J., Cortet, J., and Gordon, I.J. 2007. Selection of feeding sites by horses at pasture: testing the anti-parasite theory. Applied Animal Behaviour Science. 108(3-4): 288-301. https://doi.org/10.1016/j.applanim.2006.11.019

Gasser, R.B., Hung, G.-C., Chilton, N.B., and Beveridge, I. 2004. Advances in developing molecular-diagnostic tools for strongyloid nematodes of equids: fundamental and applied implications. Molecular and Cellular Probes. 18(1): 3-16. https://doi.org/10.1016/j.mcp.2003.10.001

Goraya, K., Iqbal, Z., Sajid, M.S., and Muhammad, G., 2013. Frequency distribution of equine diseases in three metropolises of the upper Punjab, Pakistan. International Journal of Agriculture and Biology. 15(6):10671074.

Haimanot, D., Addise, A., Tilahun, Z., and Girma, K. 2015. Prevalence of strongyle infection in horses and donkeys in and around dangila town, northwest Ethiopia. Acta Parasitologica Globalis. 6(1): 14-19. https:// doi.org/10.5829/idosi.apg.2015.6.1.9159

Herd, R. 1993. Control strategies for ruminant and equine parasites to counter resistance, encystment, and ecotoxicity in the USA. Veterinary Parasitology. 48(1-4): 327-336. https://doi.org/10.1016/0304-4017(93) 90166-K

Hutchinson, G., Abba, S., and Mfitilodze, M. 1989. Seasonal translation of equine strongyle infective larvae to herbage in tropical Australia. Veterinary Parasitology. 33(3-4): 251-263. https://doi.org/10.1016/03044017(89)90135-0

Jubb, K., Kennedy, P., and Palmer, N. 1985. Pathology of domestic animals. New York: Academic Press. Inc. p.64-165.

Keyyu, J., Kyvsgaard, N., Monrad, J., and Kassuku, A. 2005. Epidemiology of gastrointestinal nematodes in cattle on traditional, small-scale dairy and large-scale dairy farms in Iringa district, Tanzania. Veterinary Parasitology. 127(3-4): 285-294. https://doi.org/10.1016/j.vetpar.2004. 10.014

Krecek, R.C., Malan F.S., Reinecke, R.K., and de Vos, V. 1987. Nematode parasites from Burchell's zebras in South Africa. Journal of Wildlife Diseases. 23(3): 404-411.

Kyvsgaard, N.C., Lindbom, J., Andreasen, L.L., Luna-Olivares, L.A., Nielsen, M.K., and Monrad, J. 2011. Prevalence of strongyles and efficacy of fenbendazole and ivermectin in working horses in El Sauce, Nicaragua. Veterinary Parasitology. 181(2-4): 248-254. https://doi.org/10.1016/ j.vetpar.2011.04.002

Lemma, D., and Abera, B. 2013. Prevalence of ovine gastrointestinal nematodes in and around Asella, South Eastern Ethiopia. Journal of Veterinary Medicine and Animal Health. 5(8): 222-228. https://doi.org/10.5897/ JVMAH12.022 
Maqsood, M., Iqbal, Z., and Chaudhry, A. 1996. Prevalence and intensity of haemonchosis with reference to breed, sex and age of sheep and goats. Pakistan Veterinary Journal. 16: 41-43.

Mohammed, A., Disassa, H., Kabeta, T., Zenebe, T., and Kebede, G. 2015. Prevalence of gastrointestinal nematodes of sheep in Gursum woreda of Eastern Hararghe Zone, Oromia Regional state, Ethiopia. Researcher. 7(8): 45-54.

Mohammed, N., Taye, M., Asha, A., and Sheferaw, D. 2016. Epizootological study of small ruminant gastrointestinal strongyles in Gamo-Gofa Zone, Southern Ethiopia. Journal of Parasitic Diseases. 40(2): 469-474. https://doi.org/10.1007/s12639-014-0528-1

Nginyi, J., Duncan, J., Mellor, D., Stear, M., Wanyangu, S., Bain, R., and Gatongi, P. 2001. Epidemiology of parasitic gastrointestinal nematode infections of ruminants on smallholder farms in central Kenya. Research in Veterinary Science. 70(1): 33-39. https://doi.org/10.1053/rvsc.2000. 0438

Nielsen, M.K. 2012. Sustainable equine parasite control: perspectives and research needs. Veterinary Parasitology. 185(1): 32-44. https://doi.org/ 10.1016/jvetpar. 2011.10.012

Nielsen, M.K., Kaplan, R.M., Thamsborg, S.M., Monrad, J., and Olsen, S.N. 2007. Climatic influences on development and survival of free-living stages of equine strongyles: implications for worm control strategies and managing anthelmintic resistance. The Veterinary Journal. 174(1): 23-32. https://doi.org/10.1016/j.tvj1.2006.05.009

Nielsen, T., Dean, R.S., Robinson, N., Massey, A., and Brennan, M.L. 2014. Survey of the UK veterinary profession: common species and conditions nominated by veterinarians in practice. The Veterinary Record. 174(13): 324. https://doi.org/10.1136/vr.101745

Pilo, C., Altea, A., Pirino, S., Nicolussi, P., Varcasia, A., Genchi, M., and Scala, A. 2012. Strongylus vulgaris (Looss, 1900) in horses in Italy: is it still a problem? Veterinary Parasitology. 184(2-4): 161-167. https:// doi.org/10.1016/j.vetpar.2011.09.016

Rehman, A., Jingdong, L., Chandio, A.A., and Hussain, I. 2017. Livestock production and population census in Pakistan: determining their relationship with agricultural GDP using econometric analysis. Information Processing in Agriculture. 4(2): 168-177. https://doi.org/10. 1016/j.inpa.2017.03.002

Requena-Méndez, A., Chiodini, P., Bisoffi, Z., Buonfrate, D., Gotuzzo, E., and Muñoz, J. 2013. The laboratory diagnosis and follow up of strongyloidiasis: a systematic review. PLoS Neglected Tropical Diseases. 7(1): e2002. https://doi.org/10.1371/journal.pntd.0002002 
Saeed, K., Qadir, Z., Ashraf, K., and Ahmad, N. 2010. Role of intrinsic and extrinsic epidemiological factors on strongylosis in horses. Journal of Animal and Plant Science. 20(4): 277-280.

Sipra, A.S., Anwar, A., and Khan, M. 1999. Studies on strongylosis in equines with special emphasis on hematology and chemotherapy. Pakistan Journal of Biological Sciences. 2(4): 1634-1636. https://doi.org/10.3923/pjbs. 1999.1634.1636

Smith, J., Sones, K., Grace, D., MacMillan, S., Tarawali, S., and Herrero, M. 2013. Beyond milk, meat, and eggs: role of livestock in food and nutrition security. Animal Frontiers. 3(1): 6-13. https://doi.org/10.2527/af.20130002

Upjohn, M.M., Shipton, K., Lerotholi, T., Attwood, G., and Verheyen, K.L. 2010. Coprological prevalence and intensity of helminth infection in working horses in Lesotho. Tropical Animal Health and Production. 42(8): 1655-1661. https://doi.org/10.1007/s11250-010-9617-z

Uslu, U., and Guclu, F. 2007. Prevalence of endoparasites in horses and donkeys in Turkey. Bulletin-Veterinary Institute in Pulawy. 51(2): 237.

Wannas, H., Dawood, K.A., and Gassem, G.A. 2012. Prevalence of gastrointestinal parasites in horses and donkeys in al diwaniyah governorate. AL-Qadisiyah Journal of Veterinary Medicine Sciences. 11(1): 148-155.

Zajac, A.M., and Conboy, G.A. 2012. Veterinary clinical parasitology. West Sussex: John Wiley and Sons. 